\title{
Advancing Diversity and Inclusivity in STEM Education
}

\author{
Sharon Mason \\ Rochester Institute of \\ Technology \\ B. Thomas Golisano College \\ of Computing and \\ Information Sciences \\ 20 Lomb Memorial Drive \\ Rochester, NY 14623-5604 \\ Sharon.Mason@ rit.edu
}

\author{
Sara Wadia-Fascetti \\ Northeastern University \\ College of Engineering \\ 110 Forsyth St. \\ Boston, MA 02115 \\ s.wadia-fascetti@neu.edu \\ Mary Deane Sorcinelli \\ College of Education \\ University of Massachusetts \\ Amherst \\ 813 North Pleasant Street \\ Amherst, MA 01003 \\ msorcinelli@acad.umass.edu
}

\begin{abstract}
Women faculty are underrepresented in science, technology, engineering and math (STEM) disciplines. The National Science Foundation ADVANCE program strives to increase the representation and advancement of women STEM faculty. This panel will present the efforts of the NSF ADVANCE Program along with specific efforts by university awardees to activate change for STEM faculty. Program elements, milestones, progress and challenges will be described along with strategies on getting started at your own university.
\end{abstract}

\section{Keywords}

Diversity, women, faculty, STEM, ADVANCE, gender.

\section{INTRODUCTION}

The National Science Foundation looks to strengthen the advancement and representation of women faculty in STEM through the ADVANCE Institutional Transformation program [1]. Specifically, the goals of the program are to:

(1) to develop systemic approaches to increase the representation and advancement of women in academic STEM careers; (2) to develop innovative and sustainable ways to promote gender equity in the STEM academic workforce; and (3) to contribute to the development of a more diverse science and engineering workforce. ADVANCE also has as its goal to contribute to and inform the general knowledge base on gender equity in the academic STEM disciplines [2].

The AdvanceRIT Institutional Transformation project (NSF ADVANCE 1209115), awarded in 2012 by the NSF, aims to increase the representation and advancement of women STEM faculty (which includes social and behavioral sciences, SBS) by removing barriers to resources that support career success and by creating new interventions and resources. Two of the five AdvanceRIT principal investigators will serve as the leads for this panel.

AdvanceRIT has adopted a multi-frame organizational analysis approach from Bolman and Deal [3] to improve understanding of organizational matters at RIT. This approach integrates several aspects of organizational theory, including structural, human resources, political, and symbolic perspectives, and suggests the

Permission to make digital or hard copies of part or all of this work for personal or classroom use is granted without fee provided that copies are not made or distributed for profit or commercial advantage and that copies bear this notice and the full citation on the first page. Copyrights for third-party components of this work must be honored. For all other uses, contact the Owner/Author.

Copyright is held by the owner/author(s).

SIGITE'16, September 28-October 1, 2016, Boston, MA, USA.

ACM 978-1-4503-4452-4/16/09

http://dx.doi.org/10.1145/2978192.29782067

use of each as a "frame" or "lens" for viewing the organization and for devising strategic interventions to change the organization [4]. The five-year, multidimensional approach to this institutional transformation project incorporates over 20 interventions which can be divided into faculty recruitment, faculty advancement, cultural change, and resource allocation impact areas.

All panelists will focus on efforts to activate organizational change for STEM faculty in order to meet ADVANCE program goals. Program elements, milestones, progress and challenges will be described along with strategies for getting started.

\section{PANELISTS}

\subsection{Dr. Margaret Bailey}

Dr. Margaret Bailey, P.E. is a professor of Mechanical Engineering and conducts research in Thermodynamics, engineering and public policy, engineering education, and gender in STEM. Dr. Bailey serves as PI for the AdvanceRIT grant, co-PI for the Advocates and Allies award and Senior Faculty Associate to the Provost for ADVANCE. In her panel presentation, Dr. Bailey will focus on the overarching AdvanceRIT program goals and several key program initiatives including the recently conducted salary study and the campus-wide unconscious bias education effort underway.

\subsubsection{Salary Study}

The AdvanceRIT team assembled a Resource Allocation Committee (RAC) in 2013 to revise and improve the process for evaluating resource equity by gender, beginning with RIT's salary equity study. Previous salary equity studies lacked transparency and campus-wide representation to inform decision- making. The RAC engages faculty and administration from across campus to understand resource allocation concerns and perceptions of the process. Collaborators include members from the AdvanceRIT leadership team, the Vice President for Strategic Planning, the Assistant Vice Presidents for Institutional Research and Human Resources, the Senior Associate Provost, a Department Head, and an Associate Dean. Comments and discussion will focus on the methodology adopted to organize and optimize the operation of this cross faculty-administration committee as well as the outcomes of their collaborative work.

\subsubsection{Unconscious Bias Education}

RIT institutionalized unconscious bias (UB) education for faculty search committees over the past seven years, although its delivery style varied by college. In 2012, AdvanceRIT began collaboratively working with key campus partners to raise the collective level of understanding regarding best practices within RIT in regards to UB education. AdvanceRIT also begin hosting UB education workshops for various audiences on campus including department heads, the Academic Senate, Promotion 
Committees, and faculty/staff in general. There have been over ten different educational experiences offered by AdvanceRIT since 2012 on our campus, with varying program lengths, styles, and intended learning outcomes. In early 2016, the Provost convened a university-wide taskforce to propose a wide-scale conceptual framework for our university to address UB education among our faculty, staff, and students. This discussion will explore the activities which led up to the university-wide taskforce assembly and the group's recommendations.

\subsection{Professor Sharon Mason}

Professor Sharon Mason is a professor in the Department of Information Sciences and Technology. Her interests include IT education, routing and switching, network design and security, management, and internetworking. Professor Mason serves as coPI on the AdvanceRIT grant, lead for the Connect Grants and coPI for the Advocates and Allies award. In her panel presentation, Professor Mason will focus on the Connect Grants and the Advocates and Allies Program.

\subsubsection{Connect Grants}

The Connect Grants are a partnership between the AdvanceRIT project and the Office of the Provost. Funding supports projects designed to foster faculty leadership and career development. The goal is to empower faculty and department heads in broadening opportunities to promote faculty career advancement. The grants also support creative efforts to guide faculty through various career stages such as tenure review, promotion to full professor or leadership position development. Discussion around the Connect Grants will focus on impact of the grants and how they contribute to the overarching institutional transformation effort.

\subsubsection{Advocates \& Allies}

In 2015, the AdvanceRIT team embarked on the Advocates \& Allies program as part of North Dakota State University (NDSU) NSF ADVANCE Plan D award \#1500604 [5]. This signature program from NDSU looks to improve gender equity through the direct and proactive engagement of male faculty with two components: Senior male faculty who research and learn about issues of gender inequality, train others and serve as Advocates; and the Allies, male faculty trained by the Advocates who become proponents in their departments for gender equity, this project focuses on men as change agents. By ensuring fair and equitable treatment of women at the university, these committed men actively and vocally promote gender diversity and equality.

Discussion around the Advocates \& Allies Program will focus on goals and benefits of engaging male faculty in institutional transformation efforts.

\subsection{Dr. Sara Wadia-Fascetti}

Dr. Sara Wadia-Fascetti serves as Associate Dean for Research and Graduate Studies within the College of Engineering at Northeastern University. She is also the Director of the Northeastern ADVANCE program and Special Assistant to the Provost for Faculty Development. She served previously as Associate Vice Provost for Faculty Advancement, working on policy development, initiatives to support faculty development, and the university-wide faculty mentoring program.

Dr. Wadia-Fascetti has been a member of the faculty in the Civil \& Environmental Engineering Department since 1994. She performs research in the use of nondestructive sensing technologies for condition assessment and diagnostics on structural systems, co-directs the VOTERS (Versatile Onboard Traffic Embedded Roaming Sensors) initiative, and is a member of the Executive Committee for NSF-funded Gordon Center for Subsurface Sensing and Imaging Systems (Gordon - CenSSIS). She directs the NSF-funded Interdisciplinary Graduate Education and Research Traineeship (IGERT) site on Intelligent Diagnosis for Aging Civil Infrastructure and serves as Director of Graduate Programs in the Civil \& Environmental Engineering Department. In her comments, Dr. Wadia-Fascetti will discuss the overall institutional transformation effort at NU and specifically focus on the programs which have been institutionalized.

\subsection{Dr. Mary Deane Sorcinelli}

Dr. Mary Deane Sorcinelli is the Distinguished Scholar in Residence, Mount Holyoke College and Senior Scholar, Bay View Alliance for Reform of STEM Undergraduate Education. She previously served as Associate Provost, Director of the Center for Teaching \& Faculty Development, Professor of Educational Policy at the University of Massachusetts Amherst, and Director, Office of Faculty Development, Indiana University Bloomington.

Dr. Deane is a well-known researcher in the areas of academic careers, faculty professional development, teaching and learning, and the evaluation of teaching. She has written over 100 articles, book chapters, and books in a wide range of sources. She holds an M.A. in English from Mount Holyoke College and an Ed.D in Educational Policy from UMass Amherst. She was awarded the University's 2013 Distinguished Alumni Award and the 2014 Lifetime Achievement Award, ACE Massachusetts Network for Women Leaders in Higher Education. Dr. Deane will focus her comments on her past involvement of various Advance institutional transformation efforts with a focus on the activities which have been most impactful in regards to faculty career navigation.

\section{ACKNOWLEDGMENTS}

Support for this research was provided by the National Science Foundation ADVANCE Institutional Transformation Catalyst (ITCatalyst) program under Award No. 0811076 and the National Science Foundation ADVANCE Institutional Transformation program under Award No. 1209115. Any opinions, findings, and conclusions or recommendations expressed in this material are those of the authors and do not necessarily reflect the views of the National Science Foundation.

\section{REFERENCES}

[1] N. S. Foundation. (July 2). NSF ADVANCE: Increasing the Participation and Advancement of Women in Academic Science and Engineering Careers. Available: https://www.nsf.gov/funding/pgm_summ.jsp?pims_id=5383

[2] M. Bailey, C. Marchetti, S. Mason, and M. Valentine, "NSF ADVANCE Institutional Transformation," ed. Rochester, NY: National Science Foundation, 2012.

[3] L. Bolman and T. Deal, Reframing organizations: Artistry, choice, and leadership. San Francisco, CA: Jossey-Bass, 1991.

[4] A. Austin, S. Laursen, A. Hunter, and M. Soto, "Organizational Change Strategies to Support the Success of Women Scholars in Science, Technology, Engineering, and Mathematics (STEM) Fields: Categories, Variations, and Issues.," presented at the Proc. Annual Conference of the American Educational Research Association, New Orleans, LA., 2011.

[5] (Nov. 3). ADVANCE North Dakota State University. Available: http://www.ndsu.edu/forward/advance forward initiatives/forward advocates and_allies/ 